\title{
Schnëssen. Surveying language dynamics in Luxembourgish with a mobile research app
}

https://doi.org/10.1515/lingvan-2019-0031

Received May 18, 2019; accepted December 7, 2019

\begin{abstract}
The mobile app Schnëssen establishes a digital and participatory research platform to collect data on present-day spoken Luxembourgish through crowdsourcing and to present the results of data analysis to the general public. Users can participate in different kinds of audio recording tasks (translation, picture naming, reading, question) as well as in sociolinguistic surveys. All audio recordings are accessible to the public via an interactive map, which allows the participants to explore variation in Luxembourgish themselves. In the first year of data collection, roughly 210.000 recordings have be collected covering numerous variation phenomena on all linguistic levels. Additionally, over 2800 sociolinguistic questionnaires have been filled out. Compiling such amounts of data, the Schnëssen app represents the largest research corpus of spoken Luxembourgish.
\end{abstract}

Keywords: Luxembourgish; Language Variation; Crowdsourcing; Smartphone application; data collection

\section{A mobile research app for Luxembourgish}

The Luxembourgish language has much variation, including regional varieties, socio-stylistic resources originating from French and German and 'free' variation that seems to be unconstrained in terms of social or linguistic categories. Many nouns, for example, allow two or more ways to indicate the plural, which cannot be traced back to regional, stylistic, or foreign language influence. These sources of variation, however, have only been researched to a limited extent, e.g. in relation to regional variation (in a comprehensive dialect atlas, i.e. Luxemburgischer Sprachatlas (Schmitt 1963), using data from before WWII) or stylistic preference for co-occurring Germanic or Romance variants (see Conrad 2017).

Luxembourg is a trilingual country with French, German and Luxembourgish as official languages in a complex sociolinguistic setting. With the languages maintained by the educational system, a large share of the population can be regarded as trilingual on a rather high competence level. While French and German serve mainly as written languages and as lingua francas in the public sphere and at the workplace $-48 \%$ of the population are non-nationals - Luxembourgish has traditionally been used as a predominantly spoken language for most purposes by 50-70\% of the total population (see Fehlen and Heinz 2016). However, with its increasing use as a written language, Luxembourgish is subject to ongoing processes of Ausbau and standardisation and can serve thus as a prime example of a young, evolving and highly 'plastic' language (see Gilles 2019b).

Against this backdrop, the project Schnëssen ${ }^{1}$ - Är Sprooch fir d'Fuerschung 'Your language for research' focuses on the surveying, analysing, and communication of variation in present-day spoken Luxembourgish.

1 Schnëssen is a Luxembourgish verb meaning 'to chat, to gossip'.

*Corresponding author: Peter Gilles, University of Luxembourg, Institute for Luxembourgish linguistics and literatures, Faculty of Humanities, Education and Social Sciences, Esch-sur-Alzette, Luxembourg, E-mail: peter.gilles@uni.lu. https://orcid.org/ 0000-0001-9216-3082

Nathalie Entringer, Sara Martin and Christoph Purschke: University of Luxembourg, Institute for Luxembourgish linguistics and literatures, Faculty of Humanities, Education and Social Sciences, Esch-sur-Alzette, Luxembourg, E-mail: nathalie.entringer@uni.lu (N. Entringer); sara.martin@uni.lu (S. Martin); christoph.purschke@uni.lu (C. Purschke) 
This includes traditional regional variants as well as contact-induced variation and other linguistically highly relevant phenomena. Methodologically, the project makes use of a dedicated mobile application developed in cooperation with the Swiss software studio ibros.ch. The technological backbone of the Schnëssen app is similar to prior applications used for other languages, focusing on recordings of audio data instead of written text.

The Schnëssen app also offers sociolinguistic questionnaires in-app via an embedded mobile website. Projects such as this which aim to collect and analyse large datasets from app surveys are a relatively young pursuit within sociolinguistics (e.g. Leemann, Kolly and Britain 2018 and Britain, Leemann and Kolly 2018 for English dialects; Leemann and Kolly 2016; Glaser et al. 2018 for Swiss German, and Hilton et al. 2017 for Frisian). The Schnëssen app is similar in its focus on mass audio recordings, but is additionally capable of changing these recording items easily without requiring an update to the app. This feature allows for the creation of successive elicitation rounds. Furthermore, continuously publishing articles with results directly in the app helps to build a community of researchers and interested lay persons.

Given the availability of excellent network coverage, the ubiquity of smartphones in the Luxembourgish population ${ }^{2}$ and the advanced technical specifications of contemporary smartphones (e.g. microphone quality), using a mobile app enables the collection of large amounts of data with comparatively little effort. In return, a lot of additional effort has to be expended in recruiting participants and disseminating results, e.g. via social media (see Section 3). In conjunction with the linguistic purpose of this study, this project also seeks to establish long-term cooperation with a community of interested citizens which will make it possible to launch follow-up surveys or use the Schnëssen platform as a proxy for student and $\mathrm{PhD}$ projects. In doing so, this project seeks to combine different strands of sociolinguistic work, i.e. the analysis of variation and change from a variationist linguistics point of view, quantitative sociolinguistics (e.g. via questionnaires about language attitudes) and citizen science, i.e. the active participation of citizens in all aspects of project work. This article focuses on the design of the smartphone application and the methods of data collection (Sections 2 and 3). Because of the recency of data collection in the project, it is not yet possible to provide detailed overall results. Sections 4 and 5 nevertheless present the overall structure of the corpus and examples of results. Sections 6 and 7 contain a discussion of the potential pitfalls of crowdsourcing in this context as well as an outlook.

\section{Methods and design}

The Schnëssen app has a modular design, offering different tasks in separate tiles (see Figure 1 and the screencast video 'Schnëssen_Demo.mp4' in the supplementary material). Before participants can take part in the recording or questionnaire tasks, they are asked to enter basic demographic information, such as place of birth, age, gender, first language, education level and language competencies. Participation is anonymous and no user registration is required to fulfil the tasks. Additionally, the app can handle multiple user profiles per device, to account for cases where e.g. a participant assists an elderly person to take part in the survey.

\subsection{Collection of audio data}

The main objective of the Schnëssen app is the documentation of a variety of linguistic phenomena contributing to the large and diverse variation of Luxembourgish. The linguistic phenomena focus on encompassing all linguistic levels (phonetics/phonology, morphology, syntax, lexicon, pragmatics). Due to the large number of phenomena, and in order to avoid burdening participants with strenuous recording sessions, data

2 In 2017, the number of mobile cellular subscriptions in Luxembourg per 100 people amounted to 136, higher than in France (106), Belgium (105) or Germany (134). See: https://data.worldbank.org/indicator/IT.CEL.SETS.P2 [last access 17.04.2020]. 


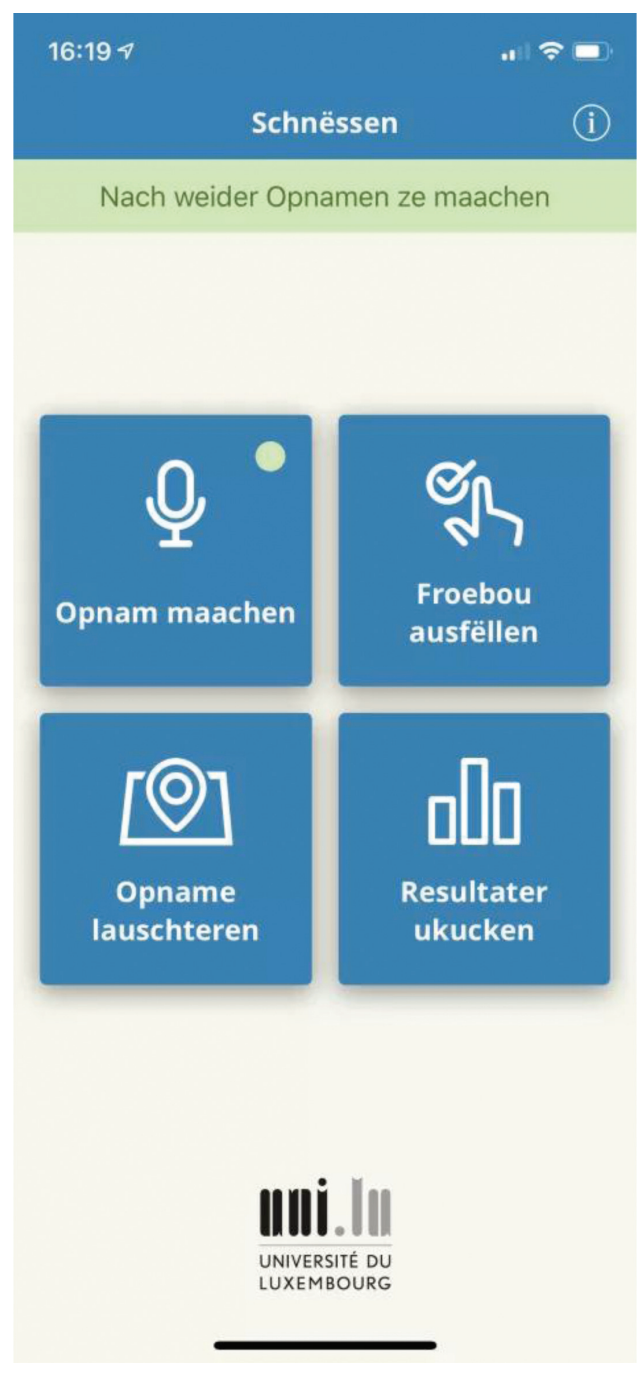

Figure 1: Screenshot of the main screen of the Schnëssen app.

collection is organised in 'rounds': each collection round is available for a couple of months and contains between 50 and 100 recording items. The fourth survey round was launched in April 2019. The first round (April to July 2018) focused on dialectological phenomena of Luxembourgish. Based on the dialect atlas from 1963 (Schmitt 1963) and further dialect surveys (e.g. Gilles 1999), a series of recording items was developed to trace regional dynamics in Luxembourgish over time and to help devise a new dialect atlas. Subsequent surveys focused on data collection for individual projects such as $\mathrm{PhD}$ theses, e.g. on issues of language standardisation or socio-pragmatic aspects of certain pronouns.

The main way in which participants engage with the app is through four different types of recording items: a translation task, a picture-naming task, a reading task and a question task. To offer the participants variety during recording sessions, these four types are mixed. Some of the items regard ongoing public debates on language purism and decay (e.g. the words for 'ant', 'hedgehog' or 'turtle') in order to help participant motivation by making the material relevant and contemporary. The most important data to collect concerns the language used in the recording tasks. In order to access the entire range of linguistic variants, it is impossible to use written (Standard) Luxembourgish. Therefore, in the translation task, participants are asked to translate short sentences from German or French to Luxembourgish. Due to the high competence of most Luxembourgers in these two languages, these translations do not pose any difficulties. As an example for the translation task, consider the German sentence Ihr fliegt vor Pfingsten nach Ägypten. 'You (pl.) are going to fly 


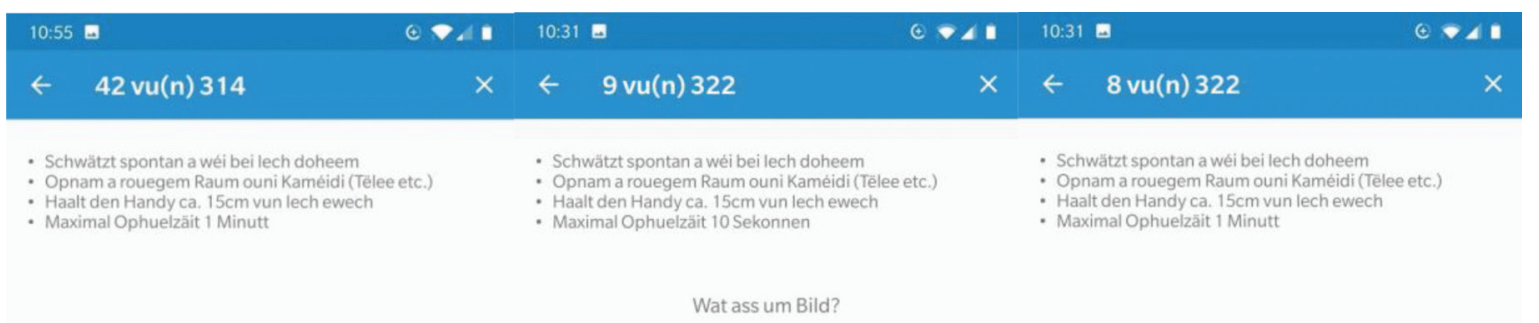

Ihr fliegt vor Pfingsten nach Ägypten.

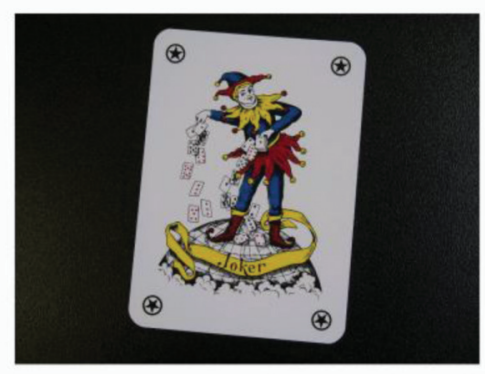

Liest dëse Saz vir:

Elo stinn ech schonn 10 Minutten um Busarrêt an de Bus ass nawell nach net komm.
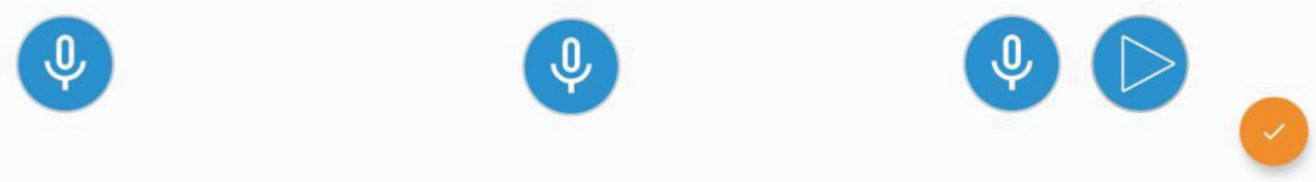

Figure 2: Screenshots of three recording tasks, from left to right: a translation task, a picture-naming task and a reading task.

to Egypt before Pentecost.' (see Figure 2). It contains (at least) five different phenomena of interest: phonological realisations for the pronoun dir 'you' ([diie / de:e]), the verb fliegt 'fly' ([flitt / flsit / flikt]), the noun Pfingsten 'Pentecost' ([pæ:Iftən / pæ:Istən / penftən / penstən] etc.), the preposition nach 'to' ([op / no]), and the country name Ägypten 'Egypt' ([e:'3ipten / e:'3yptən / ع:'gyptən] etc.). Using translations such as these, it is possible to survey a very large number of phenomena (more than 500 so far) within a very limited number of translation items.

Due to the typological closeness of Luxembourgish and German, we primarily use German as the default language for the translation items, except in cases where the priming effect might be too strong; where a German word is too close to its Luxembourgish counterpart, a French sentence is used instead. Nevertheless, especially in the case of lexical variation and due to language contact, priming effects for some items can only be avoided by using pictures. Hence, the picture-naming task is intended to collect Luxembourgish words for certain graphical representations of everyday items or concepts, e.g. the playing card shown in Figure 2 (Luxembourgish Joker ['zəuke / 'dzəoke] or Stippi ['Jtipi]]).

In the reading task, participants are asked to read a sentence containing linguistic phenomena that cannot be easily influenced by Luxembourgish orthography. In the example in Figure 2, this is the case for the ubiquitous word Busarrêt 'bus stop', which has been included in order to analyse word internal obstruent voicing, as in ['busare:] vs. ['buzane:]).

Finally, in the question task, participants answer short questions in relation to specific lexical items or pragmatic aspects (e.g. 'What is the word for the institution where convicted people are sent to?' - Gefängnis/Prison 'prison'; 'How do you greet a foreign person?' - Moien/Salut/Zali/Bonjour). This task is additionally designed in such a way to help detect a participant's preference towards loan vocabulary from either French or German.

By clicking on the microphone button, participants can begin the audio recording for an item. The transfer of recorded audio data is done on a per-item basis, allowing the participant to interrupt and continue the 


\begin{tabular}{|c|c|c|c|c|c|c|c|c|c|c|c|c|c|c|c|}
\hline A & B & c & D & E & $\mathrm{F}$ & G & H & ' & J & $k$ & $L$ & M & N & 0 & 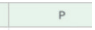 \\
\hline \multirow{2}{*}{\multicolumn{6}{|c|}{ Eine Frau hat am Freitag die schwarzen Kleider genäht. }} & \multirow{2}{*}{\multicolumn{10}{|c|}{ 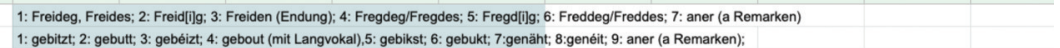 }} \\
\hline & & & & & & & & & & & & & & & \\
\hline pictu $=r$ & rec $=$ & $=$ recordingUR $=r$ & record $=s$ & surveyiD1 & F Ofspillen & $=$ Freitag & $\bar{F}$ Remarken_F $F \overline{ }$ & genäht & $=$ Remarken_g $\bar{F}$ & Variant_gent $\overline{-}$ & Variant_Freit $=$ & RE__bitzen & $\bar{F}$ Alter & $\mp$ Geschlecht & Ausbildung \\
\hline 6 & 112 & 2 https://uxappsda & 322 & & 9 Ofspillen & & 7 Fraddig & & 4 & gebout & Aner & RE & 25 bis 34 & Männlech & Fachhéichsc \\
\hline 6 & 112 & 2 https:/luxappsda & 424 & & 17 Ofspillen & & 1 & & 2 & gebutt & Freideg/Freide & & 25 bis 34 & Weiblech & Fachhéichse \\
\hline 6 & 112 & 2 https:/luxappsda & 523 & & 18 Ofspillen & & 1 & & 1 & gebitzt & Freideg/Freide & le kee $R E ̈$ & 25 bis 34 & Weiblech & Fachhéichsc \\
\hline 6 & 112 & 2 https:/luxappsda & 558 & & 19 Ofspillen & & 1 & & 1 & gebitzt & Freideg/Freide & le kee RE & 25 bis 34 & Männlech & Fachhéichsc \\
\hline 6 & 112 & 2 https:/luxappsda & 610 & & 20 Ofspillen & & 1 & & 1 & gebitzt & Freideg/Freide & le kee RË & 25 bis 34 & weiblech & Fachhéichsc \\
\hline 6 & 112 & 2 https:/luxappsda & 712 & & 23 Ofspillen & & 3 & & 1 & gebitzt & Freiden & kee $\mathrm{RE}$ & 25 bis 34 & Weiblech & Fachhéichsc \\
\hline 6 & 112 & 2 https:/luxappsda & 814 & & 24 Ofspillen & & 1 & & 1 & gebitzt & Freideg/Freide & le kee RE & 25 bis 34 & Weiblech & Fachheichse \\
\hline 6 & 112 & 2 https:/luxappsda & 957 & & 25 Ofspillen & & 1 & & 1 & gebitzt & Freideg/Freide & le kee RË & 35 bis 44 & Weiblech & Fachhéichsc \\
\hline 6 & 112 & 2 https://uxappsda & 1067 & & 26 Ofspillen & & 3 & & 2 & gebutt & Freiden & RE & 25 bis 34 & Weiblech & Fachhéichsc \\
\hline 6 & 112 & 2 https:/luxaappsda & 1168 & & 27 Ofspillen & & 7 Freddig & & 1 & gebitzt & Aner & kee RË & 55 bis 64 & Weiblech & 1e CLycée c \\
\hline 6 & 112 & $2 \mathrm{https} / / / \mathrm{uxappsda}$ & 1346 & & 30 Ofspillen & & 1 & & 2 & gebutt & Freideg/Freide & & 25 bis 34 & Weiblech & Fachhéichsc \\
\hline 6 & 112 & 2 https:/nuxappsda & 1367 & & 31 Ofspillen & & 1 & & 1 & gebitzt & Freideg/Freide & le kee RË & 45 bis 54 & Weiblech & CCP/DAP (CH \\
\hline 6 & 112 & 2 https:/luxappsda & 11223 & & 36 Ofspillen & & 3 & & 10 gebützt & Aner & Freiden & Aner & 35 bis 44 & Weiblech & Fachhéichsc \\
\hline 6 & 112 & 2 https://luxappsda & 1560 & & 39 Ofspillen & & 3 & & 1 & gebitzt & Freiden & kee $\mathrm{RE}$ & 45 bis 54 & Weiblech & CCP/DAP (CH \\
\hline 6 & 112 & 2 https:/luxappssda & 2735 & & 116 Ofspillen & & 1 & & 1 & gebitzt & Freideg/Freide & le kee RË & 35 bis 44 & Weiblech & Fachheichsc \\
\hline 6 & 112 & 2 https:/huxappsda & 2902 & & 124 Ofspillen & & 3 & & 1 & gebitzt & Freiden & kee $\mathrm{RE}$ & 25 bis 34 & Weiblech & Fachhéichsc \\
\hline 6 & 112 & 2 https:/nuxappsda & 2982 & & 126 Ofspillen & & 3 & & 2 & gebutt & Freiden & RË & 25 bis 34 & Weiblech & Fachheíchse \\
\hline 6 & 112 & 2 https:/lluxappsda & 2964 & & 127 Ofspillen & & 3 & & 1 & gebitzt & Freiden & kee $\mathrm{RE}$ & 35 bis 44 & Männlech & Fachhéichsc \\
\hline 6 & 112 & 2 https:/luxappsda & 3016 & & 128 Ofspillen & & 1 & & 1 & gebitzt & Freideg/Freide & le kee $R E ̈$ & 25 bis 34 & Männlech & Fachhéichse \\
\hline 6 & 112 & 2 https:/nuxappsda & 3071 & & 129 Ofspillen & & 1 & & 1 & gebitzt & Freideg/Freide & le kee RË & 55 bis 64 & Weiblech & Fachhéichsc \\
\hline 6 & 112 & 2 https://uxaposda & 3185 & & 130 Ofspillen & & 2 & & 1 & gebitzt & Freidig & kee RE & 35 bis 44 & Weiblech & Fachhéichsc \\
\hline 6 & 112 & 2 https:/luxuappsda & 3243 & & 131 Ofspillen & & 3 & & 2 & gebutt & Freiden & RE & 25 bis 34 & weiblech & 1e CLycée c \\
\hline a & 112 & o hthe-/ht wranneda & 1ก२६3 & & 123 Ofenillan & & 2 & & 1 & vahityt & Fraidan & Ken PF & 25 hic $\Delta 4$ & Waihlarh & Farhháicher \\
\hline
\end{tabular}

Figure 3: Screenshot of an annotation table in a Google Spreadsheet.

recording session at any time. The sound files are recorded in uncompressed WAV-format, sampled at 44.1 $\mathrm{kHz}$. For the analysis of lexical, morphological or syntactic aspects, virtually all recordings can be used. Concerning (articulatory or acoustic) phonetic investigations, some recordings have to be discarded due to bad sound quality, e.g. when recordings were made in a noisy environment such as in a car, on the bus or in a restaurant.

In general, this method of data elicitation has successfully produced results in line with the expected outcomes for the different phenomena. Given the nature of the unsupervised survey method, however, there is always the possibility that participants interpret the instructions differently than intended. This is predominantly the case when participants translate items using a divergent word order or alternative syntactic construction. Such instances aside, there has been very little misuse of the app so far (e.g. deliberately making wrong entries or unrelated recordings). The overwhelming majority of participants in fact report a rather serious disposition toward using the app. Many also evaluate the project very positively in a free feedback recording item at the end of the survey.

All content used for the different tasks is managed centrally via a server frontend. This makes it possible to add new items, reorder existing items, correct mistakes and to reactivate entire prior survey rounds if necessary or appropriate. Having this flexibility makes it possible to launch new survey rounds at any time, allowing us thus to be able to react to current events and trends in public discourse (see Section 3). All sound files are stored on a dedicated server including a unique (anonymous) identifier to reference the files with the associated user profile. To facilitate (manual) analysis, recordings and user profiles are organised in Google Spreadsheets, allowing collaborative work on the annotations. The screenshot in Figure 3 illustrates one such annotation spreadsheet.

\subsection{Sociolinguistic questionnaire}

Luxembourg's sociolinguistic make-up, with its complex relationships between Luxembourgish, French and German, is a prevailing topic in public discourse, be it in the news, in private or on public transport. In order to contextualise the linguistic choices participants make in the recording task and to gain a deeper understanding of language awareness, preferences, ideologies and attitudes, a sociolinguistic questionnaire is included in the Schnëssen app. The questionnaire is designed with a quantitative approach, asking participants to evaluate short statements on five-point Likert scales or in forced-choice questions (see Figure 4). In doing so, different aspects of the participants' perceptions and evaluations of everyday social practices can be addressed, such as language choices in typical everyday situations, assessments of linguistic and 


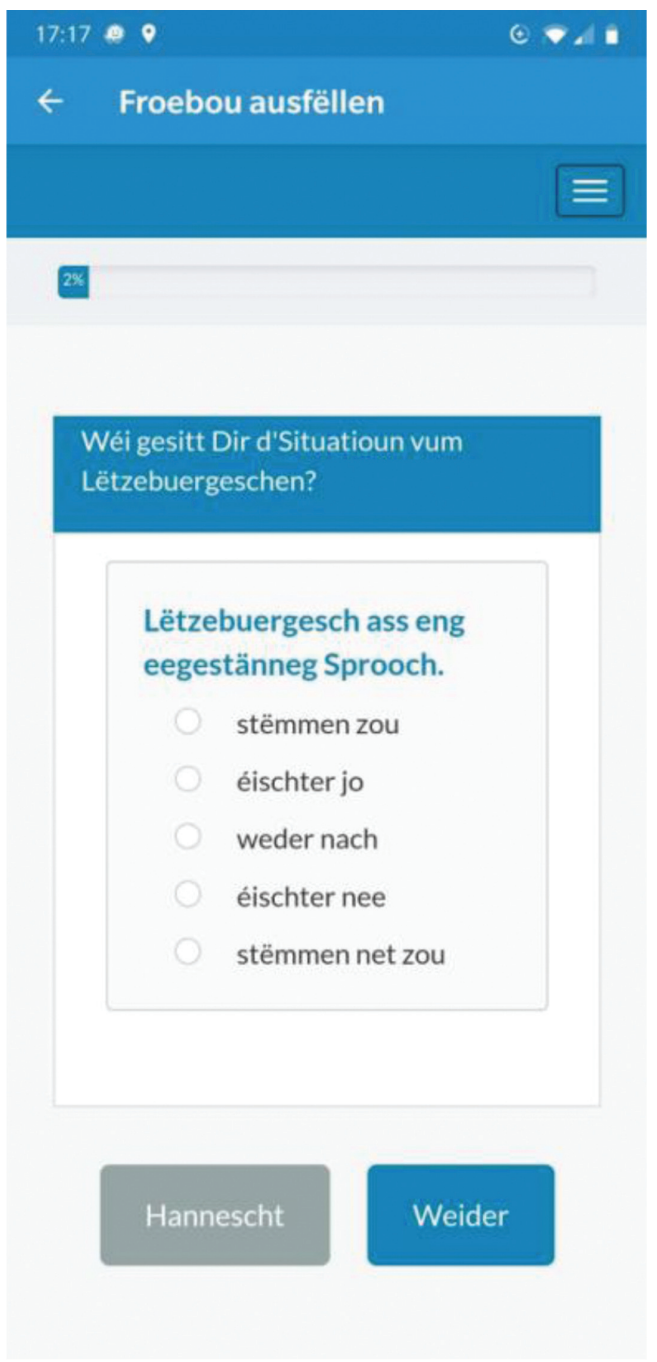

Figure 4: Screenshot of a forced-choice survey question in the sociolinguistic questionnaire.

cultural diversity in Luxembourg, personal norm horizons in relation to correctness, and social positionings vis-à-vis language policy and change in Luxembourgish (for a general overview of attitudes towards multilingualism in Luxembourg, see Fehlen 2009; for the theoretical basis of this quantitative approach to attitudes, see Purschke 2015). In a subsequent analysis, the results of this study will be correlated with the participants' speech production in the recording tasks. The questionnaire is hosted on a LimeSurvey server (LimeSurvey 2003ff), which can be embedded directly into the app via a mobile website. This allows for flexible administration, updating and even replacement of the survey entirely without needing to update the app itself.

\subsection{Presentation of data and results}

All audio recordings are accessible to the public via an in-app map (see Figure 5). Zooming in and out reveals all the locations for which recordings have been submitted, with the number in the circles indicating the number of participants per location. Selecting a location opens a list of all items that have been recorded in this location. Selecting an item from this list then further displays the list of individual recordings together with the age groups of the respective participants and a time stamp of the recording (see Figure 5). 


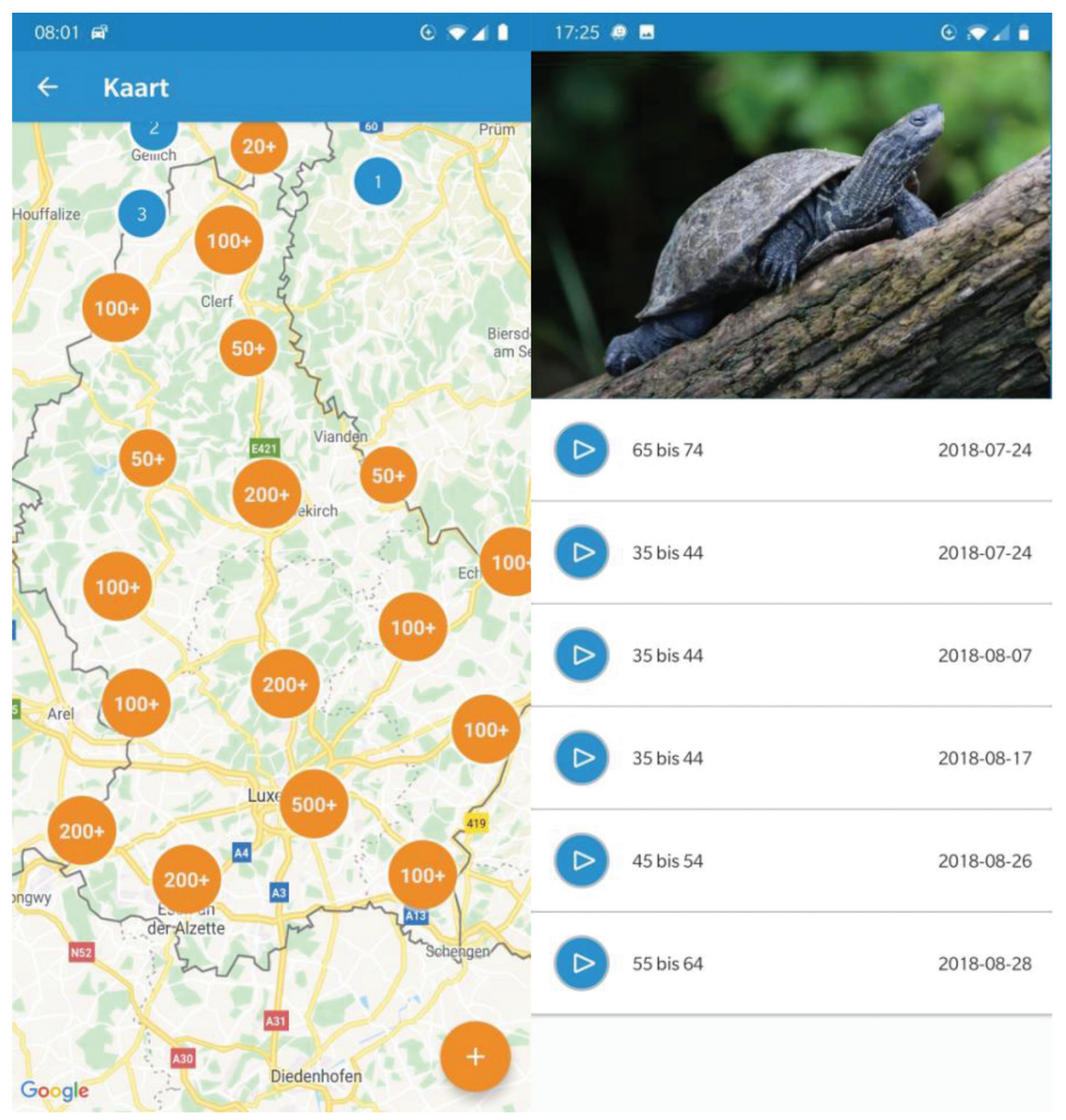

Figure 5: Screenshot of audio recordings on a map and as a list.

Selected survey results are published in the results section of the app to inform participants about project progress and to demonstrate how the submitted data are being processed. This feature distinguishes Schnëssen from similar apps, which do not tend to share their results so publicly. Shorter results articles analyse specific variation phenomena which could be of interest to the wider public and provide visualisations of quantitative aspects, e.g. frequencies of linguistic variants and distribution by age group, education level or gender. Variation phenomena with a regional distribution are presented in linguistic maps. The example article in Figure 6 (left) shows the results of a survey question on the active language of the participants' mobile phones. Figure 6 (right) illustrates the regional variants for the negation particle net 'not' ([nət], [nit], [nik], [nek]). To best cater to and attract the Luxembourgish public, all articles and in-app texts are written entirely in Luxembourgish. In addition, the results are published on the project's website ${ }^{3}$ as well as on our social media accounts. ${ }^{4}$

3 https://infolux.uni.lu/schnessen.

4 Facebook: https://facebook.com/Schnessen, Twitter: https://twitter.com/schnessen. 


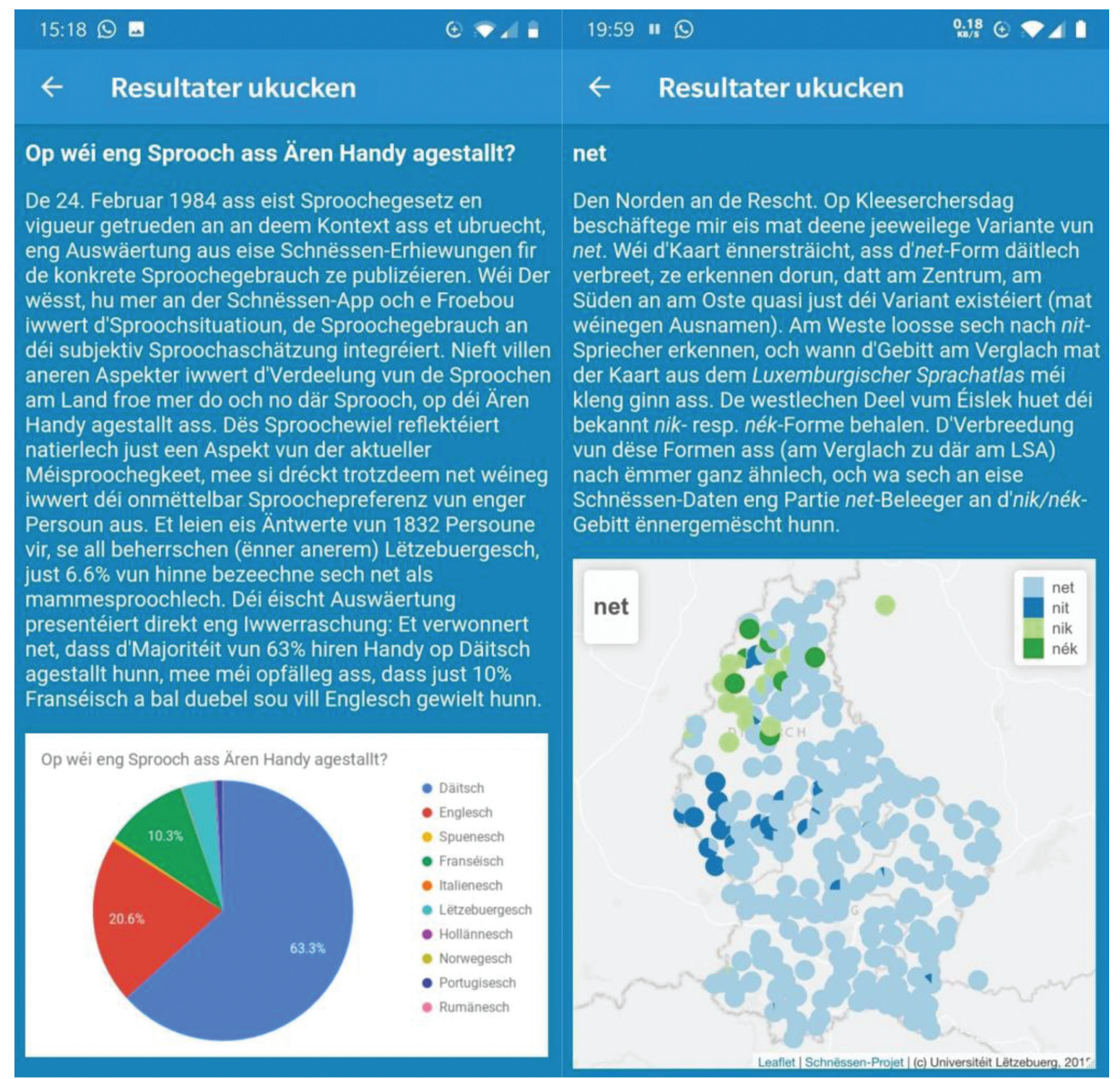

Figure 6: Screenshots of the result section.

\section{Participant recruitment and community building}

In order to draw the public's attention to the app, recruit participants and build a community of linguistically interested citizens, we employ a variety of communication channels and strategies.

Firstly, we set up a Facebook page, the most widely used social network in Luxembourg, which is currently at 1200 likes. Since the app release in April 2018, Facebook has been used to keep the participants informed about the app in general, to share news about recently added tasks and to share the processes and results of data collection and analysis (see Figure 7). This helps to maintain public interest and motivation and functions as a direct method of interaction. This page also serves as a reward mechanism for the community, illustrating the direct outcome of their contributions.

To initiate interaction, those who have liked the Facebook page are asked to vote on which results analysis should be published next. Special news items are also used as a topical starting point for outreach activities whenever possible, e.g. results for the phonological variation of Fussball 'football' during the 2018 FIFA 


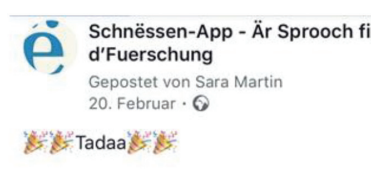

Et ass erëm Zäit fir nei Resultater a well haut anscheinend den Liebe-dein-Haustier-Tag 43 resp. den Love Your Pet Day 89 ass, hu mir eis, wärend mer eis nach froen, wéi deen Dag da wuel op Lëtzebuergesch heescht - Hief-däin-Hausdéier-gärDag Ho oder sou ähnlech? (Maacht Är Propos gären an de Commentairen)-, eppes Passendes zum Thema erausgesicht an eis mat de Bezeechnungen Hond, Mupp a Co. 60 auserneegesat. Ofgefrot hu me dëst an eiser App mat Hëllef vun engem GIF, op deem zwee Hënn (méi genau: Corgien) op engem Lafband ze gesi waren.

Prett fir d'Resulater?! ( 950 Opnamen)

a "Mupp" vs. "Hond": 62,5\% vun de Leit hunn eng Variant vun "Hond" an 34,6\% eng Variant vun "Mupp" an d'App erageschwat.

$\Rightarrow$ Den "Hond" dominéiert a bal all Altersgrupp méi oder manner staark, woubäi den "Mupp" méi dacks vun eelere Leit @enannt gouf (zu 43-45\%) wéi vun deene Jonken 숭 (knapp 26\%).

$$
\Rightarrow \quad 00
$$

Figure 7: Screenshots of the Facebook app page.

World Cup. This is intended to not only motivate potential participants to contribute to the survey but also to generate media attention.

Two of the core aims of this Facebook page are to try to encourage the interested public to engage with our analysis of a specific linguistic phenomenon while at the same time trying to attract people to use the app. While the Facebook page has created a lot of interaction through comments, shares and likes, only a slight increase in the participation rate in the app itself can be observed as a direct consequence of this kind of social media campaigning. The same holds true for placing (paid) ads for the app on Facebook. Other media outlets have proven to be much more effective in this regard.

The 'traditional' media outlets - newspaper, radio and television - have become an important means for reaching the broader public. The app has been presented through interviews in print media and on a dedicated online science platform for the general public. ${ }^{5}$ Most importantly, the app has been promoted through interviews and reports on RTL (radio, television, news portal, mobile application), the media group with the highest outreach in Luxembourg. Unsurprisingly, the collaboration with RTL had the greatest impact on app usage. RTL has published articles about the app in general, updates, new content and results. In a twelve-part 'summer series' during the summer holidays of 2018, app results were published online twice a week over a period of 6 weeks. These contributions were also briefly teased on RTL Radio. Taken together, the online articles have attracted a large number of participants to submit new recordings. The success of the cooperation with RTL also becomes apparent in Figure 8, depicting the evolution of the number of recordings per day: peaks in submission mostly correlate with instances of media coverage. Even if this connection is not always directly traceable, our survey proves that regular media campaigning can have a positive effect on the number of participants.

Another successful outreach activity was a citizen science workshop where the participants could research the collected data themselves together with the project team. Thirteen participants were introduced to the project and were trained to analyse and annotate recordings and to create maps and graphs. The focus

$\overline{5}$ https://science.lu/de/schnessen-fuer-die-wissenschaft/forscher-sammeln-mit-app-informationen-ueber-die-landessprache [last access 17.04.2020]. 


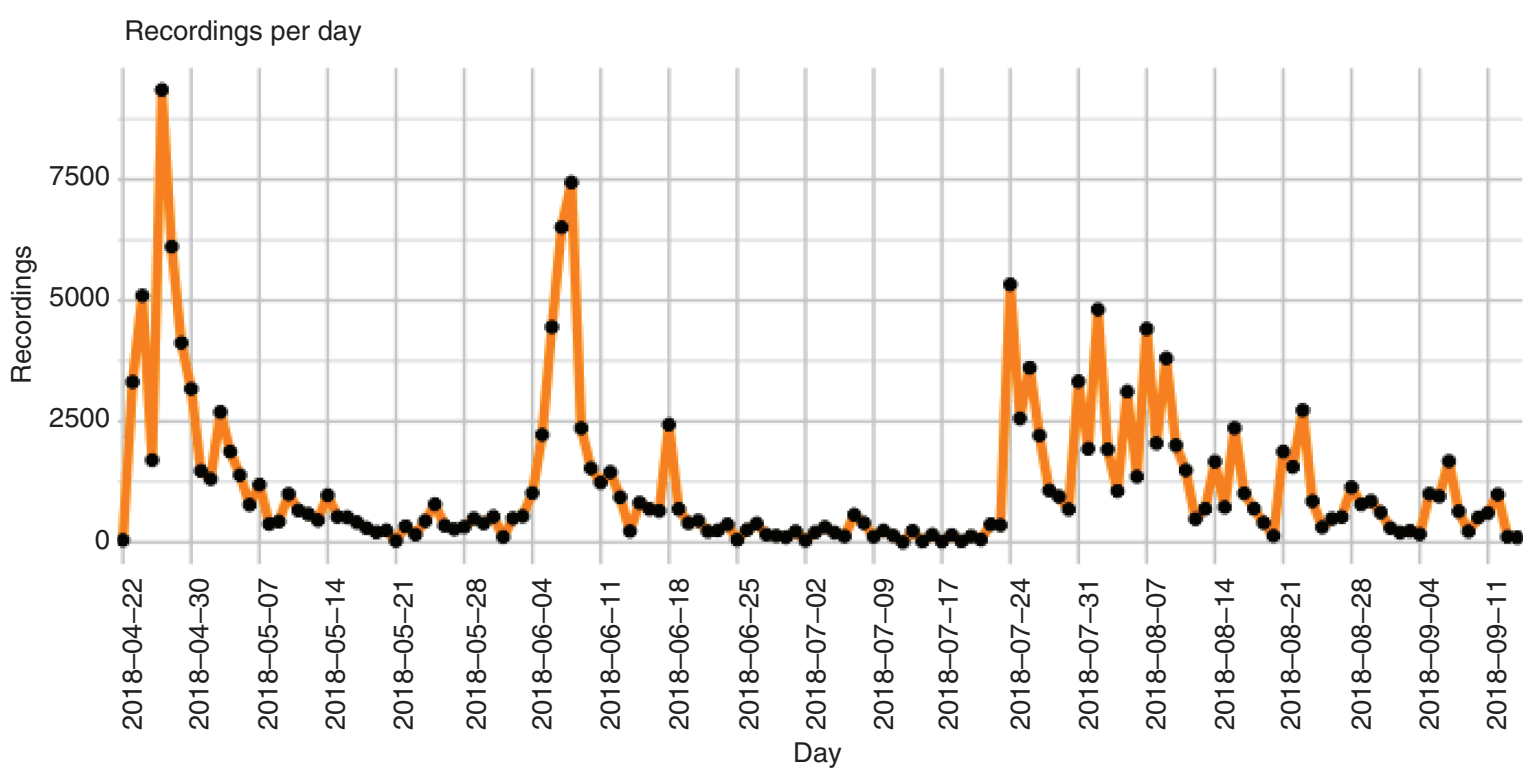

Figure 8: Received recordings per day in the Schnëssen app from 22.04.2018 to 11.09.2018.

of this workshop was not only the collaborative analysis of data but also the active involvement of participants in research activities. Giving the participants an insight into the daily work of a linguist and enabling them to pursue their own research interests allowed us to strengthen our ties with the participant community.

\section{Corpus statistics}

Due to the high awareness of language-related topics in the Luxembourgish speech community and the success of our media campaigning, participant recruitment and motivation has turned out to be a relatively easy task. Since its release in April 2018, the app has been downloaded 7900 times (Android: 2700, iOS: 5200) and is currently installed on 2500 devices (Android: 1200, iOS: 1300), which is a good user retention rate compared with other specialized apps that do not serve a specific everyday use.

Across the four survey rounds of audio tasks, which took place between April 2018 and March 2019, we have received more than 210.000 individual recordings from nearly 3500 speakers in total (see Table 1). The number of items to record per round varied between 56 and 100, totalling 330 across all four rounds. A full recording session for all items in a given round takes approximately 20-30 minutes to complete. The length of all audio recordings collected so far totals approximately 180 hours (assuming 3 seconds per recording), which constitutes the largest corpus of spoken Luxembourgish in existence.

As is typical for this kind of survey, many participants only open the app once, to get an impression and record a few of the first items, never then returning to or continuing with their submissions. Across all four rounds, our participants nevertheless made 70 recordings on average. Only a few participants have contributed more than 100 recordings. Purschke (forthcoming) identifies similar participation patterns for the

Table 1: Overall results of the app-based recording tasks.

\begin{tabular}{lrrr}
\hline & Recording items & Range of participants per item & Recordings \\
\hline Round 1 (April '18) & 100 & $820-2100$ & 110.000 \\
Round 2 (July '18) & 100 & $180-1370$ & 76.600 \\
Round 3 (October '18) & 74 & $190-430$ & 20.400 \\
Round 4 (March '19) & 56 & $150-230$ & 9.200 \\
Total & 330 & & 216.200 \\
\hline
\end{tabular}




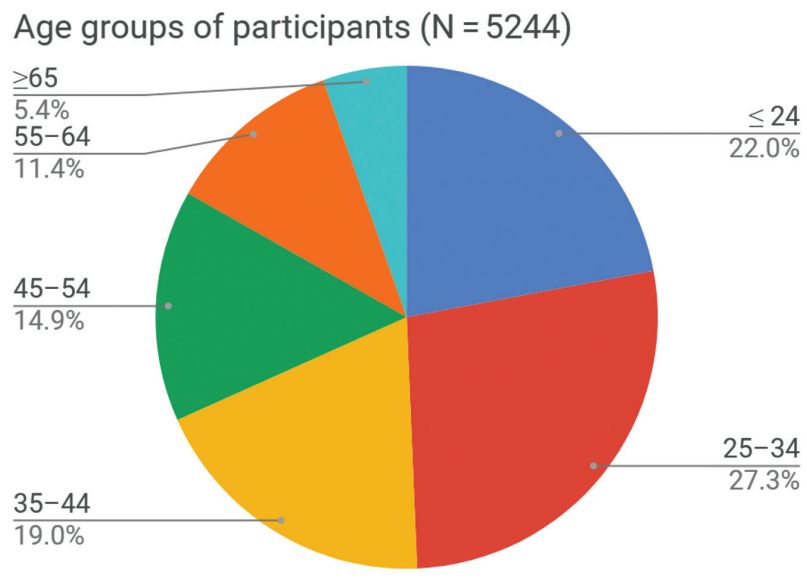

Figure 9: Distribution of participants per age group.

linguistic landscape research app Lingscape, distinguishing between casual users with a low participation level and regular and power users.

Representativeness in scientific data is difficult to quantify, even more so for heterogeneous data originating from unsupervised crowdsourcing tasks. The following numbers may nevertheless give an indication of the relative size of the collected data. Assuming a total community of approximately 320.000 speakers of Luxembourgish (see Fehlen and Heinz 2016), for the first round of data collection, and depending on the recording item, between $0.3 \%$ (820 participants) and $0.7 \%$ (2100 participants) of this population are ostensibly present in the sample. To reach a comparable participation rate in e.g. Germany it would be necessary to recruit between 249.000 and 581.000 participants (assuming a total of 83 million speakers). Over 2800 participants answered the sociolinguistic questionnaire, many of whom also participated in the audio recording tasks.

As for the demographic profile of the participant population, roughly two-thirds are female. About $90 \%$ of all participants state that Luxembourgish is a first language, while $10 \%$ indicate that they have learned Luxembourgish as a foreign language. With respect to regional distribution, participants originate from virtually every location in Luxembourg, as well as from approximately 100 villages outside Luxembourg. For the $400+$ locations in Luxembourg, most participants come from the densely populated urbanised areas in the centre and in the south, but also the lesser populated rural areas show fairly high participation rates in relation to the total number of inhabitants. The geographical reach of this data is thus country-wide. Distribution across age groups (see Figure 9) is fairly even until the age group 45-54. For the two oldest age groups, the participation rate is lower, a common observation in app-driven projects and crowdsourced data.

\section{First results}

Due to the systematic composition of the recording tasks, the collected data covers the linguistic structure of Luxembourgish and its regional and sociolinguistic variation comprehensively, referring to the entire phonological system, large parts of morphology, selected aspects of syntax and pragmatics and numerous lexical items, among others. The dataset is sufficient to devise a new dialectological atlas, to study morphological and syntactic variation as well as (phonological, morphological and lexical) language contact with German and French. As data collection has only started recently, the following contains only initial findings.

The first results of this data have already been published in Gilles (2019a), who investigates the ongoing merger of the fricatives [6] and [J] for the minimal pair frech 'cheeky'/Fräsch 'frog' using audio data from 1300 participants across all age groups. Due to this large database, it is possible to trace the spread of this merger through differing age groups. The high sound quality of the recordings also allowed for automatic phonetic segmentation with the MAUS system (see Winkelmann et al. 2017) and subsequent acoustic phonetic analysis. Martin (2019) and Baumgartner et al. (forthcoming) study the socio-pragmatic constraints for the distribution 
of the two (feminine and neuter) personal pronouns used to refer to female persons, si 'she' and hatt 'it'. By simulating age differences and degrees of familiarity between female reference persons in various sentences in the recording tasks, the complex socio-pragmatic grounding and current change for these two pronouns can be clarified.

A further example of the potential of our data concerns phonological variation of the word Freideg 'Friday'. The regional distribution of variants for this word is well known from the dialectological atlas from 1963 (Schmitt 1963). Comparing the historical data to the variants we find in our dataset, it is possible to trace language change in Luxembourgish, e.g. the ongoing dialect levelling. The item has been embedded in a translation task and can be analysed based on approximately 1400 recordings (see Figure 10). To create the type of map pictured using pie charts containing the distribution of variants per location, the plotting functions of $R$ (R Core Team 2019) were used. In our workflow for analysis, information is retrieved dynamically from data tables (see Figure 3), making the updating of maps and other visualisations easy whenever new recordings arrive through the app. The HTML versions of these maps offer the possibility to zoom in on the map and to listen to the audio recordings of all locations by clicking on a given pie chart (see the HTML version 'friday.html' in the supplementary material). As can be seen from the juxtaposition of the two dialectological maps below, some striking changes have occurred: the northern area with the velarised forms Fregdeg ['frægdə6] (red), Fregdig ['frægdic] (orange) seems to still be stable today, but has decreased in size when compared with the old atlas; the variant Freddeg ['fRædəG] (light orange), which was present in a larger north-eastern area, can hardly be found anymore; and most importantly, the variant Freiden ['frardən] (dark green), which was documented previously only for a small region in the south-west, can be found in the entire country according to our data, and is now challenging the standard variant Freideg ['fRardə6] (dark blue). This example thus underlines the ongoing restructuring of the Luxembourgish dialect-geography.

The ongoing shift in the regional distribution of variants can be linked to changes across the age groups of the speakers. In brief, Figure 11 depicts an apparent-time analysis, illustrating a correlation between the usage of the variant Freideg (dark blue) and older age, and an inverse correlation for usage of Freiden (dark green), i.e. over time Freideg is being replaced by Freiden. As expected, the change towards a new variant
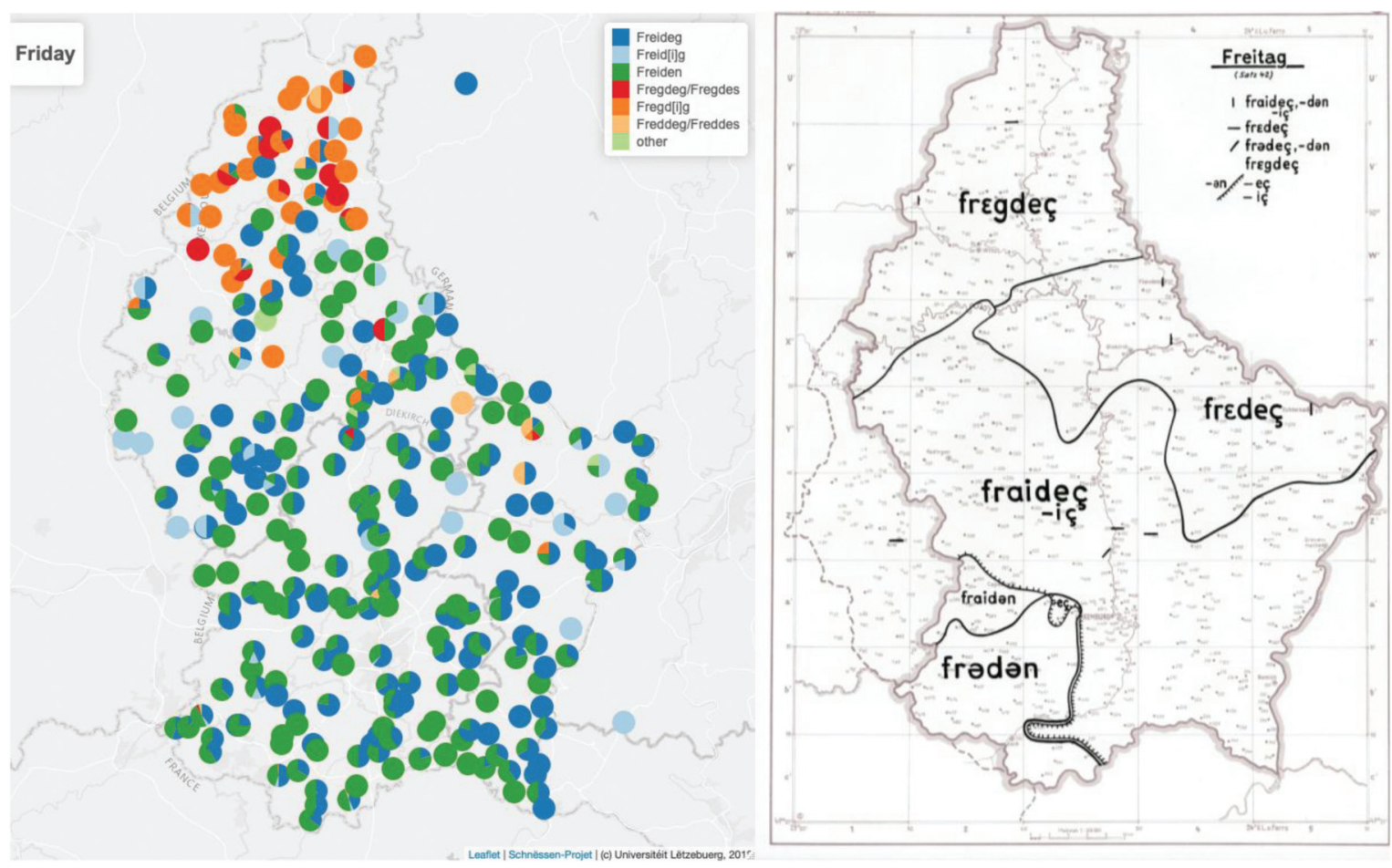

Figure 10: Regional variation for Freideg 'Friday': juxtaposition of the results for the present-day (left) and the historical situation (right; map 109 from LSA (Schmitt 1963)). 


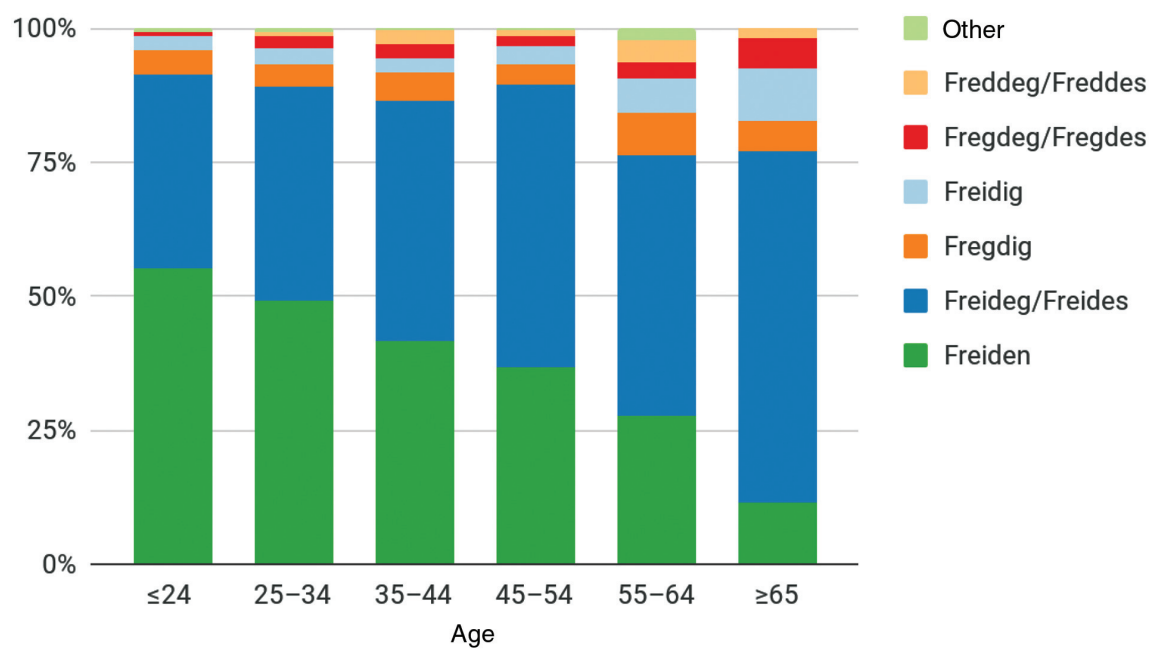

Figure 11: Apparent-time analysis for the variants of Freideg 'Friday’ across six age groups.

is mainly driven by younger people. The large dataset (here 1400 recordings) shows a rather homogenous distribution across the age groups and is therefore, in combination with the careful interpretation of further social parameters, suitable for apparent-time studies. This dataset has thus great potential in allowing for analyses of patterns of language variation and change in great quantitative detail.

\section{Potential pitfalls of crowdsourcing}

Crowdsourcing, as has been shown in this study, is evidently an effective method for compiling a large audio corpus. For under-researched languages such as Luxembourgish, this becomes a crucial tool in achieving a comprehensive overview of present-day language variation. The results gathered through this process can also then facilitate in-depth studies on specific aspects of language variation and change.

There are however limitations to the collected data: the (rather classical) method of translating from one language to another is likely to generate more experimental than spontaneous language data and the structure of the source language (here German and French) may influence the resulting translation. This influence might be less pronounced for phonological or morphological phenomena, but can play a role for lexical or syntactical phenomena. Through careful design and testing of the translation tasks, these potential problems have been limited as far as possible.

A general drawback of nearly all crowdsourcing activities is that they rely on volunteers and might thus run into the risk of demographic bias: since there is hardly any reward mechanism for participation, it is likely to mainly reach participants who are intrinsically motivated to contribute data and to support research. Similarly, those who are typically less interested in aspects of language use or do not have easy access to today's digital infrastructures are more difficult to reach. In the case of the Schnëssen app, these factors led primarily to biases in gender (more women than men) and age (more younger speakers than elderly speakers), which must be taken into account in any research. While such a demographic bias is typical for technologically driven projects, there are ways to reduce the influence of this bias on corpus structure. For example, we are encouraging participants to (assist and) record their parents and grandparents. Apart from such limitations, we are able to collect data from a broad range of demographic groups including different education levels, dialect regions and language competencies.

Another demographic aspect to consider relates to the target audience of the app. While we are specifically targeting fluent speakers of Luxembourgish (by app design and media campaigning), we would also like to collect data from speakers with Luxembourgish as a second language. Given the amount of detailed knowledge required, however, e.g. for the naming task and the high language requirements for the translation task, the app is likely to be prohibitive for many speakers and thus limits our potential audience to a subsample of 
the speech community that is likely to be Luxembourgish by nationality and trilingual. Thus, many aspects related to contact-induced variation (e.g. with Portuguese or Italian) or learner varieties of Luxembourgish are missing in the data set.

One of the main criticisms in relation to crowdsourced data relates to the quality and reliability of the collected data in general (see Lewandowski and Specht 2015). In our case, not only is the data collected with the Schnëssen app demographically biased, but we can also expect over-reporting of rare regional variants that are either not actively used by the speakers ("remembered forms") or used specifically to demonstrate "Luxembourgishness" despite current developments in language change ("desirable forms"). Given the vast amount of phenomena and speakers from different demographic groups and locations, however, the dataset allows for a wide range of apparent-time analyses, helping to mitigate these problems. The results of the Schnëssen survey can thus provide invaluable insights into present-day variation and change in spoken Luxembourgish, especially in comparison with small-scale in-depth studies of specific locations or phenomena.

\section{Outlook}

The first year of the Schnëssen app has been very successful, with a large number of participants contributing recordings and completing questionnaires despite the time-consuming design of the different tasks. After the initial peak in participation at launch, there is now a degree of stagnation within our participant community. Although we are still receiving recordings and questionnaires daily, participation rate is far below the first few months after release. The sheer quantity and linguistic richness of the data collected so far is nevertheless (often more than) sufficient to study all originally compiled research questions. The next release of the app will contain a push notification function to directly inform participants about new recording items, questionnaires or results. By adding gamification elements (quizzes etc.), which are used for example in the Gschmöis app for Swiss German (Glaser et al. 2018), participants might be better encouraged to take part.

Alongside this update, the app will be further developed into a research tool for $\mathrm{PhD}$ candidates and student projects, allowing them to access our pool of participants and to launch personal projects and experiments within the app. Other starting points for further analysis include (semi-)automatic segmentation and annotation of recordings using machine learning algorithms.

\section{References}

Baumgartner, Gerda, Simone Busley, Julia Fritzinger \& Sara Martin. forthcoming. Dat Anna, et Charlotte und s Heidi: Neutrale Genuszuweisung bei Referenz auf Frauen als überregionales Phänomen. In Helen Christen, Brigitte Ganswindt, Joachim Herrgen \& Jürgen Erich Schmidt (eds.), Regiolekt - Der neue Dialekt? Akten des 6. Kongresses der Internationalen Gesellschaft für Dialektologie des Deutschen (IGDD). Stuttgart: Steiner.

Conrad, François. 2017. Variation durch Sprachkontakt. Lautliche Dubletten im Luxemburgischen (Études Luxembourgeoises/Luxemburg-Studien 14). Frankfurt: Peter Lang.

Fehlen, Fernand. 2009. BaleineBis: une enquête sur un marché linguistique multilingue en profonde mutation. Luxemburgs Sprachenmarkt im Wandel. Luxembourg: SESOPI Centre intercommunautaire.

Fehlen, Fernand \& Andreas Heinz. 2016. Die Luxemburger Mehrsprachigkeit. Ergebnisse einer Volkszählung. Bielefeld: Transcript.

Gilles, Peter. 1999. Dialektausgleich im Lëtzebuergeschen. Zur phonetisch-phonologischen Fokussierung einer Nationalsprache. Tübingen: Niemeyer.

Gilles, Peter. 2019a. Using crowd-sourced data to analyse the ongoing merger of [6] and [] in Luxembourgish. In Sasha Calhoun, Paola Escudero, Marija Tabain \& Paul Warren (eds.), Proceedings of the 19th International Congress of Phonetic Sciences, Melbourne, Australia 2019, 1590-1594. Canberra, Australia: Australasian Speech Science and Technology Association Inc. http://intro2psycholing.net/ICPhS/papers/ICPhS_1639.pdf.

Gilles, Peter. 2019b. 40. Komplexe Überdachung II: Luxemburg. Die Genese einer neuen Nationalsprache. In Joachim Herrgen \& Jürgen Erich Schmidt (eds.), Language and Space - An International Handbook of Linguistic Variation. Vol. 4 Deutsch, 10139-1060 (Handbücher zur Sprach- und Kommunikationswissenschaft/Handbooks of Linguistics and Communication Science (HSK) 30.4.). Berlin/New York: De Gruyter Mouton. 
Glaser, Elvira, Sandro Bachmann, Anja Hasse \& Daniel Wanitsch. 2018. gschmöis - Die Smartphone-App zum Schweizerdeutschen. Mobile app for iOS and Android.

Hilton, Nanna, Hanneke Loerts, Willem Visser, Goffe Jensma, Charlotte Gooskens, Daniel Wanitsch \& Adrian Leemann. 2017. Stimmen: A Citizen Science App for Languages. University of Groningen. Mobile app for iOS and Android.

Leemann, Adrian, Marie-José Kolly. 2016. Big Data for analyses of small-scale regional variation: A case study on sound change in Swiss German. In Christoph Draxler \& Felicitas Kleber, Tagungsband der 12. Tagung Phonetik und Phonologie im deutschsprachigen Raum. P und P12. München. https://doi.org/10.5282/ubm/epub.29405.

Lewandowski, Eva, \& Hannah Specht. 2015. Influence of volunteer and project characteristics on data quality of biological surveys. Conservation Biology 29(3). 713-723.

LimeSurvey GmbH. 2003ff. LimeSurvey - An open source survey tool. Hamburg: LimeSurvey Development Team.

Martin, Sara. 2019. Hatt or si? Neuter and feminine gender assignment in reference to female persons in Luxembourgish. In Antje Dammel \& Corinna Handschuh (eds.), special issue of Language Typology and Universals (STUF), 573-601.

Purschke, Christoph. 2015. REACT - A constructivist theoretic framework for attitudes. In Dennis Preston \& Alexei Prikhodkine (eds.), Responses to Language Varieties: Variability, processes and outcomes, 37-54. Amsterdam/Philadelphia: John Benjamins.

Purschke, Christoph. forthcoming. Exploring the Linguistic Landscape of Cities through Crowdsourced Data. In Stanley Brunn \& Roland Kehrein (eds.), Handbook of the changing world language map. Heidelberg: Springer.

R Core Team. 2019. $R$ : A language and environment for statistical computing. Vienna. Austria: R Foundation for Statistical Computing.

Schmitt, Ludwig Erich (ed.). 1963. Luxemburgischer Sprachatlas. Laut- und Formatlas von Robert Bruch. Marburg: Elwert. (Deutscher Sprachatlas. Regionale Sprachatlanten 2).

Winkelmann, Raphael, Jonathan Harrington \& Klaus Jänsch. 2017. EMU-SDMS: Advanced speech database management and analysis in R. Computer Speech \& Language 45. 392-410. 